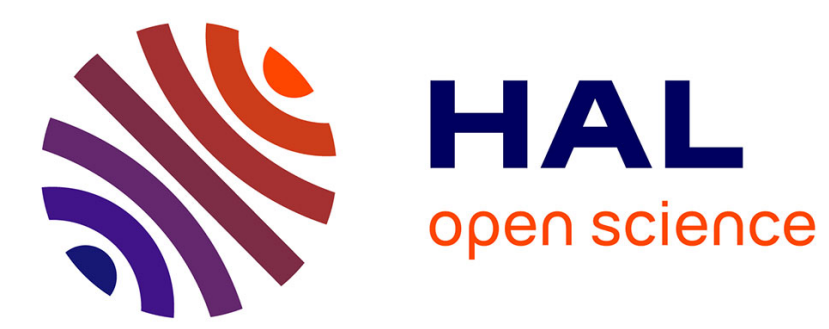

\title{
Thermal radiation in dust flame propagation
}

Christophe Proust, Rim Ben Moussa, Mohamed Guessasma, Saleh Khashayar, Jérôme Fortin

\section{To cite this version:}

Christophe Proust, Rim Ben Moussa, Mohamed Guessasma, Saleh Khashayar, Jérôme Fortin. Thermal radiation in dust flame propagation. 11. International symposium on hazards, prevention, and mitigation of industrial explosions (ISHPMIE), Jul 2016, Dalian, China. ineris-01863027

\section{HAL Id: ineris-01863027 \\ https://hal-ineris.archives-ouvertes.fr/ineris-01863027}

Submitted on 28 Aug 2018

HAL is a multi-disciplinary open access archive for the deposit and dissemination of scientific research documents, whether they are published or not. The documents may come from teaching and research institutions in France or abroad, or from public or private research centers.
L'archive ouverte pluridisciplinaire HAL, est destinée au dépôt et à la diffusion de documents scientifiques de niveau recherche, publiés ou non, émanant des établissements d'enseignement et de recherche français ou étrangers, des laboratoires publics ou privés. 


\title{
Thermal radiation in dust flame propagation
}

\author{
Proust Christophe ${ }^{a, b}$, Ben Moussa Rym ${ }^{\mathrm{b}}$, Guessasma Mohamed ${ }^{c}$, Saleh Khashayar ${ }^{b}$, Fortin \\ Jérôme $^{c}$ \\ ${ }^{a}$ Institut de l'environnement industriel et des risques, PARC ALATA, BP2, Verneuil en \\ Halatte, 60550, France \\ ${ }^{b}$ Sorbonne Universities, Technological University technologique of Compiègne, Escom, \\ Centre Pierre Guillaumat, TIMR, bat E-D, Compiègne, 60200, France \\ ${ }^{c}$ Université de Picardie Jules Verne, Laboratoire des Technologies Innovantes, LTI-EA 3899, \\ Saint Quentin, 02000 France \\ E-mail : christophe.proust@ineris.fr
}

The role of thermal radiation in premixed flame propagation has been a matter of debate for decades. And it is not only a challenging scientific point, it has significant practical implications. For instance, a route to explain the Buncefield explosion (HSL, 2009) was the implication of tiny particles raised by the blast and promoting flame acceleration through enhanced heat exchanges by thermal radiation in the flame front. In dust explosion protection, the flame is implicitly supposed to propagate like a in a gaseous mixtures but if thermal radiation is dominant for some dusts, many aspects concerning the way to mitigate the explosions for those particular dusts would need to be revised (Proust and al., 2013) . In this paper, new experimental measurements of thermal radiation in dust flames (methane air, methane air seeded with inert particles, aluminum dust air flames) are presented together with a physical interpretation.

Keywords: dust explosions, flame propagation, thermal radiation

\section{Introduction}

Dust explosions remain quite frequent in industrially developed countries despite significant progresses made during the last few decades not only about the understanding of the underlying explosion development processes (see for instance Eckhoff, 2003; Proust, 2006) but also in the mitigation techniques (Snoeys and al., 2010). A recent survey in France confirms that dust explosions concern all industrial fields because about $75 \%$ of the dusts manipulated are sufficiently combustible to explode (Janès and Chaineaux, 2010).

To a large extent, those progresses were possible because a rather close connection was made between the flame propagation mechanisms in premixed gases and in dust flames so that a large body of knowledge could be more or less directly transferred from the first field to the the second one.

In particular, it was demonstrated that for a large number of dusts, the heat is being transferred into the reactants by thermal conduction and the particles vaporise/pyrolyse so that at least part of the combustion proceeds in gaseous phase.

Is it true however, if the particles do not vaporize or produce large amounts of solids so that heat transfer by radiation might appear and play a role ? How would it modify the flame propagation process ? In case a strong influence would be found would the actual body of 
knowledge about dust explosion mitigation apply? And in which industrial field could it be a potential problem ?

In the following, a short literature survey is proposed to help answering the first and the last question and then new preliminary experimental data are presented to try and address part of the remaining questions.

\section{Is it really a problem ?}

The question of the incidence of the thermal radiation on the flame propagation processes has been raised since decades (Cassel and al., 1949; Kudryavtsev and al., 1982 ; Deshaies and Joulin ; 1985 ; Escot-Bocanegra, 2007 ; Bidabadi and al., 2013) and no satisfactory answer could be given until now, partly because of the difficulties to measure the influence, but also because of the difficulty to model the thermal radiation transfer in a suspension of particles.

Cassel model can be used to illustrate the potential influence (a deeper analysis was presented in Proust and al., 2013). Cassel extented the «Le Châtelier » approach by incorporating the heat transferred by radiation (Figure 1), solving the thermal balance in the burning zone (between $\mathrm{T}_{\text {inf }}$ and $\mathrm{T}_{\mathrm{ad}}$ ) and assuming heat transferred by radiation follows the Beer-Lambert's law $\left(Q_{\text {ext }}\right.$ stands for the extinction coefficient of the radiation and is about 2 when the size of the particle is large as compared to the wavelength of the incident light according to van den Hulst, 1981):

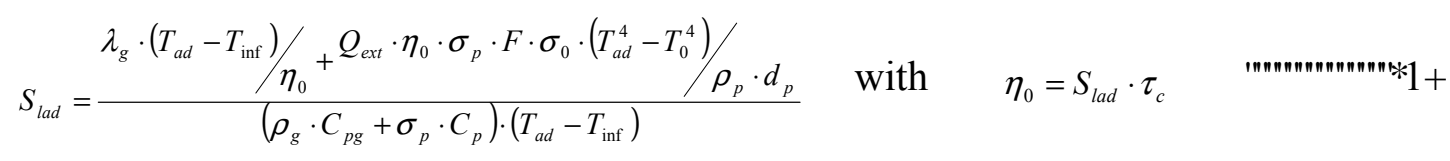

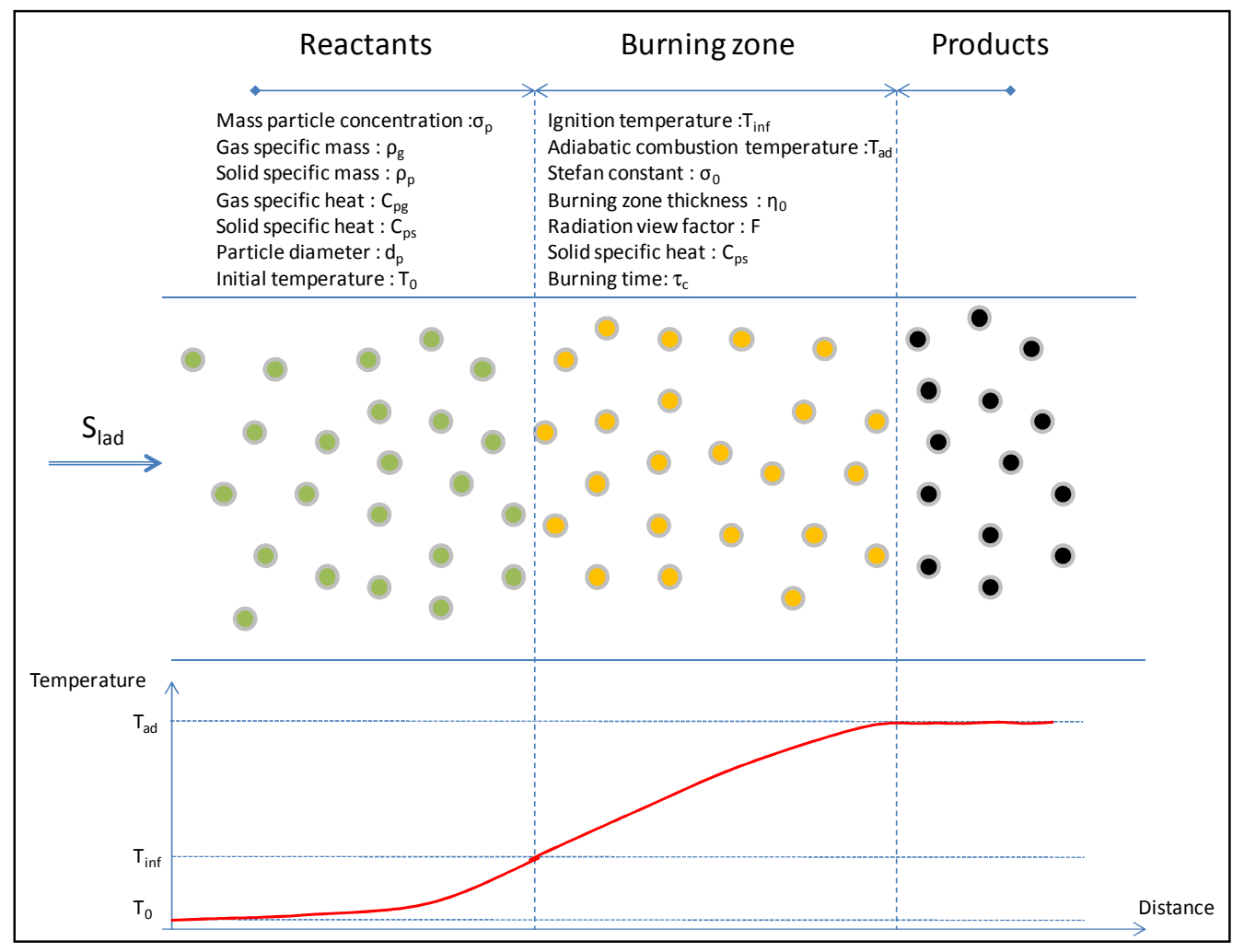

Fig. 1. Cassel's problem and definitions

The view factor defines the geometry of the flame front. If the latter is flat $\mathrm{F}=1$, if it is convex towards the reactants, $\mathrm{F}<1$ and if it is concave ("tulip" flame) $\mathrm{F}>1$. 
A numerical application is possible considering for instance aluminium dust air flames since the burning characteristics of individual particles has been investigated for long (Bazyn and al., 2007 ; Mohan and al., 2009; Goroshin et al., 2007 ; Escot-Bocanegra, 2007, Huang and al., 2007, 2009). The required parameters $T_{i n f}, T_{a d}$ and $\tau_{c}$ are given on figure 2.
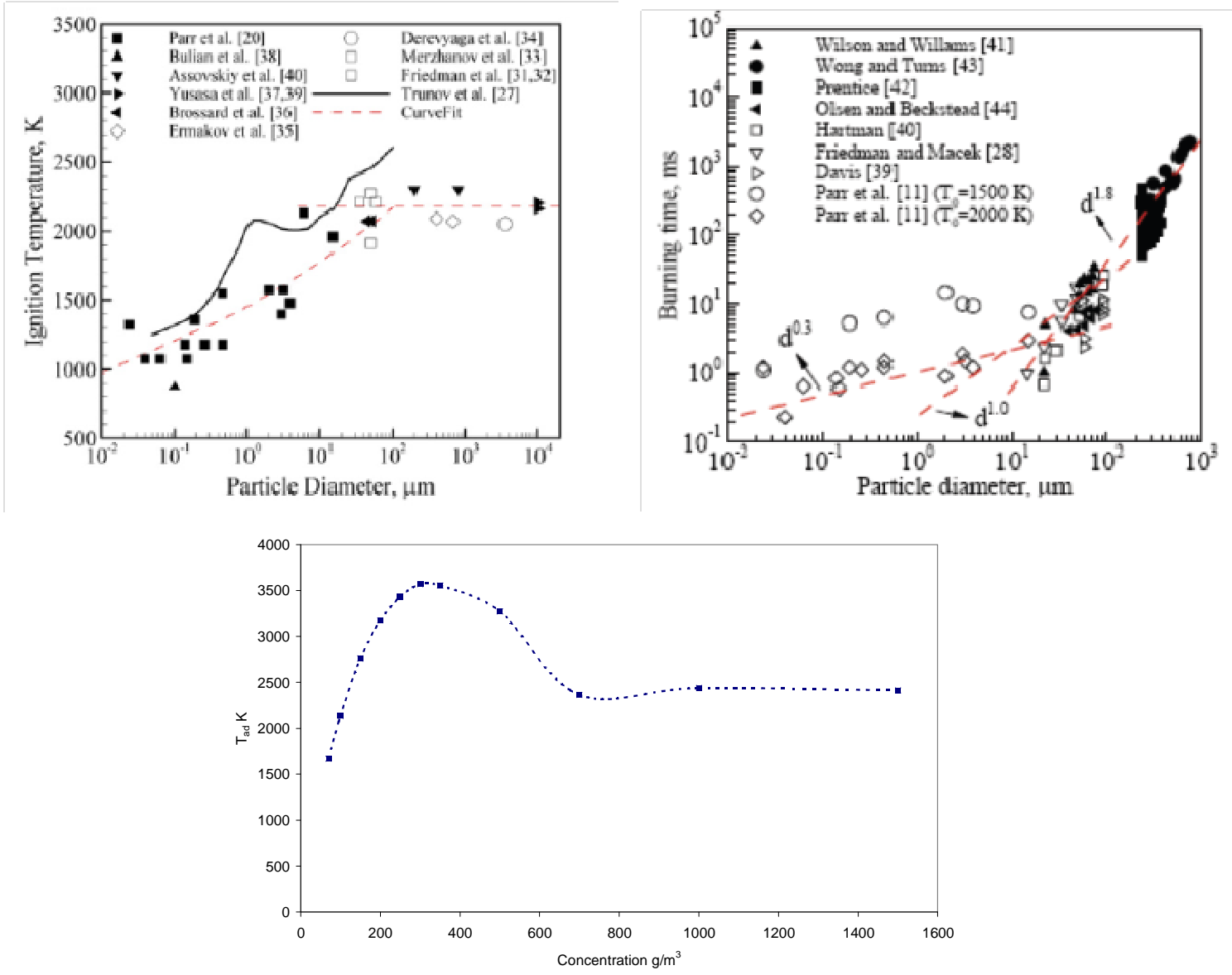

Fig. 2. $T_{i n f}, T_{a d}$ and $\tau_{c}$ from the literature (computations for $T_{a d}$ )

It is then possible to calculate the laminar burning velocity of $\mathrm{Al}$ dust-air clouds in situations where heat transfer by thermal radiation is negligible (small experimental device, large particles, convex flame,...) and the agreement with experimental data seems reasonable (Figure 3).

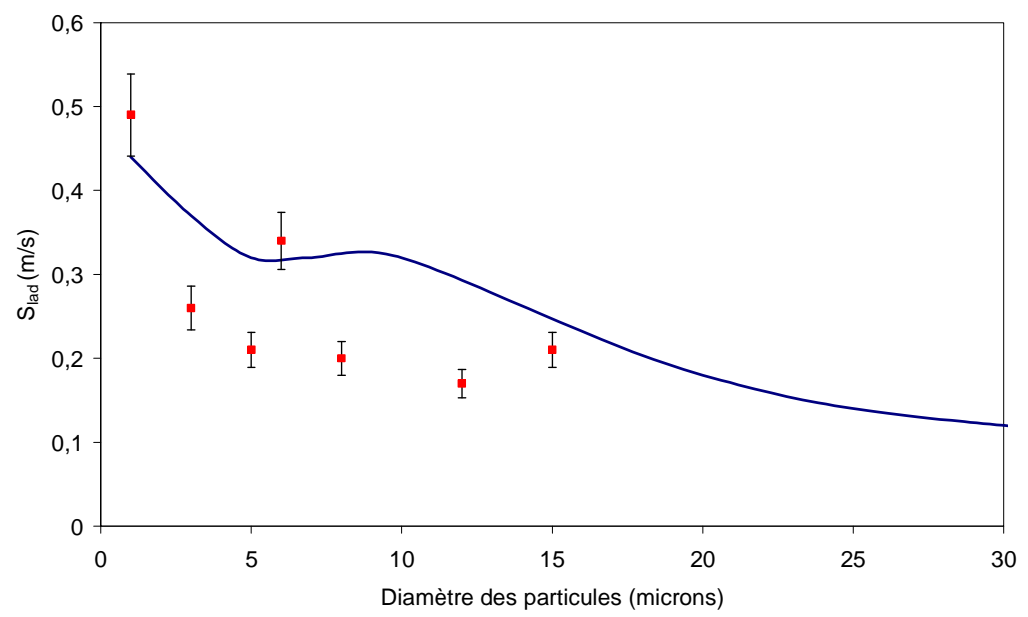


Fig. 3. Slad estimated using Cassel approximation and experimental data from Schevchuk and al., 1988

Using information from figure 3 and 2 , it comes out that the flame thickness $\eta_{0}$ (in fact the burning zone thickness) is not that different from $1 \mathrm{~mm}$ whatever the particle size. With this information, the conductive and radiative fluxes can be compared in equation $\mathrm{Qu}$ by dividing the former by the latter to obtain a sort Boltzmann number (F was set to 1 ):

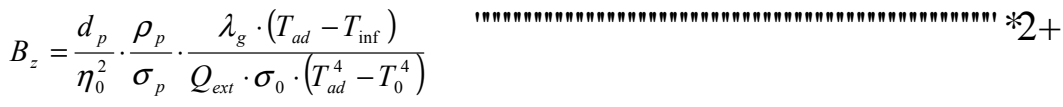

For microns size particles, $\mathrm{T}_{\text {inf }}$ is about $1700 \mathrm{~K}, \mathrm{~T}_{\mathrm{ad}} 3500 \mathrm{~K}$ in the stiochiometric conditions $\sigma_{\mathrm{p}}=0.25 \mathrm{~kg} / \mathrm{m}^{3}\left(\lambda_{\mathrm{g}}=0.1 \mathrm{~W} / \mathrm{mK}\right.$ at $\left.\mathrm{T}_{\text {inf }}, \sigma_{0}=5.67 .10^{-8} \mathrm{~W} / \mathrm{m}^{2} \mathrm{~K}^{4}, \mathrm{Q}_{\mathrm{ext}}=2, \rho_{\mathrm{p}}=2700 \mathrm{~kg} / \mathrm{m}^{3}\right)$ so that the amount of heat transferred by radiation is theoretically comparable to that transferred by heat conduction for particles of about $10 \mu \mathrm{m}$.

For smaller particles, heat transfer by radiation could be dominating and what would happen then ? Assume that the flame, initially strongly convex $(\mathrm{F}=0)$ is abruptly disturbed (by a pressure wave for instance) and become concave so that $\mathrm{F}$ goes from 0 to 2 . It can be calculated using equation (1) that $\mathrm{S}_{\mathrm{lad}}$ should increase in a larger extent the smaller the particles (Figure 4). In the example give, $S_{\text {lad }}$ is increase by a factor 4 . Since at the same time the total flame area could have been increased by the disturbance, large flame acceleration could result, much stronger than for conduction dominated flames.

To the present authors' knowledge, there is only indirect observation of the potential role of thermal radiation in the flame propagation process. Proust (Proust, 2006) demonstrated that it is possible to ignite Al dust-air clouds using a laser beam having the same intensity and wavelength than the theoretical radiated heat flux by the burning particles. Schevchuk (Schevchuk and al., 1983) relates that, observing the upward and downward Al dust-air flame propagation in a vertical tube, a surprising very fast flame acceleration was observed in the downward direction. More recently, performing closed bomb experiments, Dufaud and Vignes (Dufaud et al., 2010 ; Vignes, 2008) noticed very different and violent combustion regimes (detonation like) when the size of $\mathrm{Al}$ particles drops below a few micrometers.

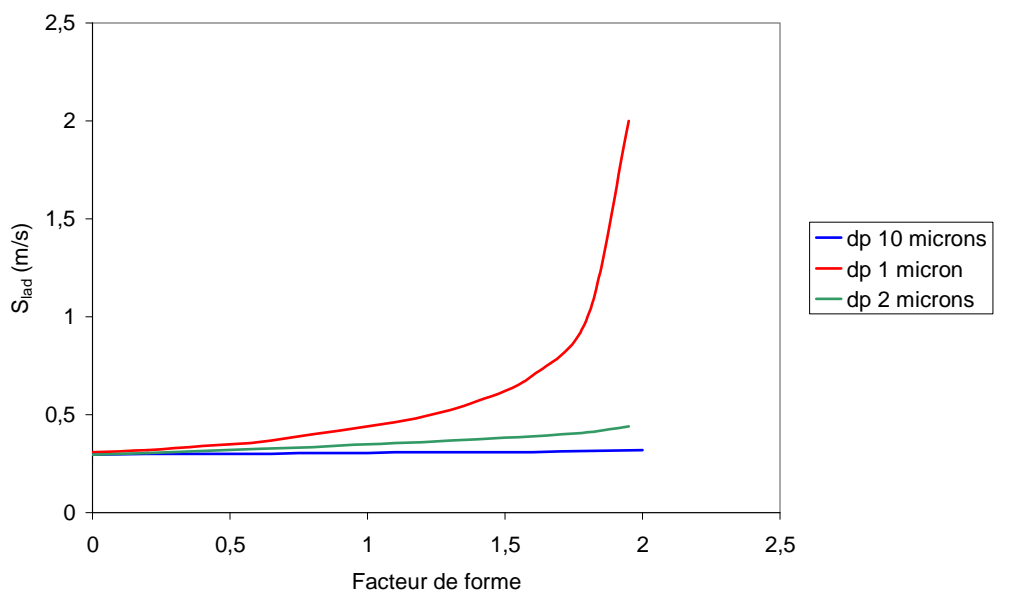

Fig. 4. Influence of $F$ on $S_{\text {lad }}$ for various Al particle size (from (1)) 
It seems then justified to investigate further this question and in particular to try and measure the amount of heat being radiated by the flame front in combustible dust-gas mixture.

\section{Setup and metrology}

\subsection{Infrastructure}

Experiments were done using the flame propagation tube (figure 5) already used in a number of studies (for instance Proust, 2006). The experimental chamber is a vertical tube (length 1.5 $\mathrm{m}$ and diameter $10 \mathrm{~cm}$ ), filled with the dust cloud by the bottom thanks to a fluidized bed device. The suspension is rising slowly upwards until complete filling (duration 30 seconds). This way, the suspension may be very homogeneous. The cloud is ignited (spark) at the bottom after having stopped the flow, shut the upper part of the tube with a gate valve and removed the suspension generator. The flame is then propagating upwards freely without being thrusted by the expansion of the burnt products which are vented out through the open end. The dust concentration is controlled by weighting the dust suspension generator before and after the tests, and measuring the volume of the gas flow.

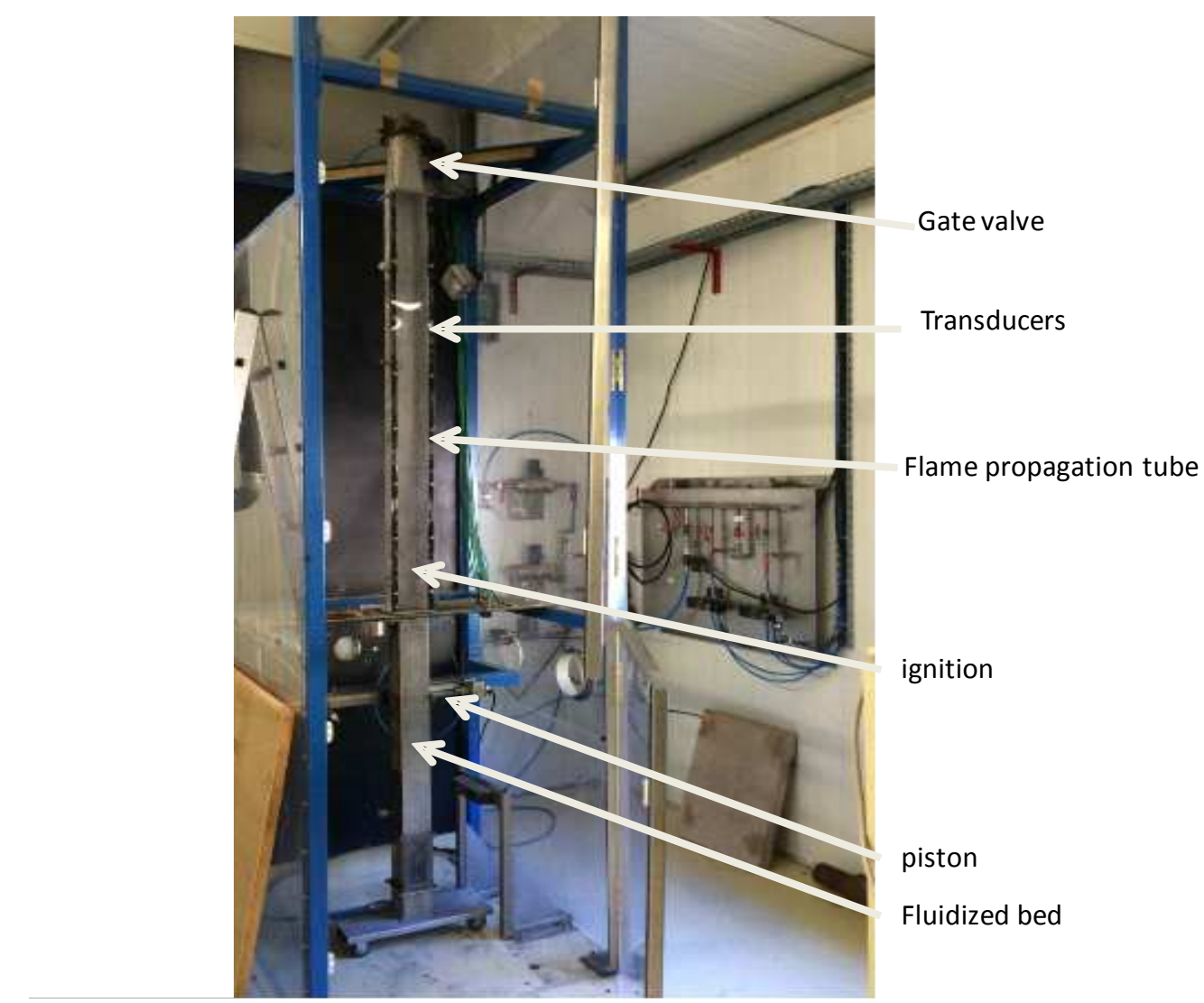

Fig. 5. Experimental setup

\subsection{Measurements}

High speed video is used to obtain an accurate measurement of the flame speed. Besides a set of transducers is used and installed at about $1 \mathrm{~m}$ from the bottom end of the tube. They are (figure 6) :

- A high voltage ionization gage, which detect the chemical zone of the flame ; 
- A collimated infrared phodiode $(0.3$ to $1.1 \mu \mathrm{m})$. The sensor is located at one extremity of a $1 \mathrm{~mm}$ internal diameter and $6 \mathrm{~cm}$ long tube. The other extremity protrudes inside the tube at $1 \mathrm{~cm}$ off the axis ;

- A fast response fluxmeter. This device (Captec technology) is a thin polymer sheet on each side of which a collection of thermocouples are inserted. On side of the sheet is glued on a cold wall acting as a reference. The voltage between both sides of the sheet is proportional to the heat received thermal flux. In this particular version of the device, optically shielded and bare strips alternate is such a way that only the radiative flux is measured. The response time is lower than $0.1 \mathrm{~s}$. The wavelength absorption range is 0.1 to $12 \mu \mathrm{m}$ i.e. over nearly all the absorption spectra of $\mathrm{CO}_{2}$ and $\mathrm{H}_{2} \mathrm{O}$. The absorptivity is 0.5 . Note the fluxmeter is "looking" in the direction of the flame while the photodiode is transversal to the direction of the propagation.

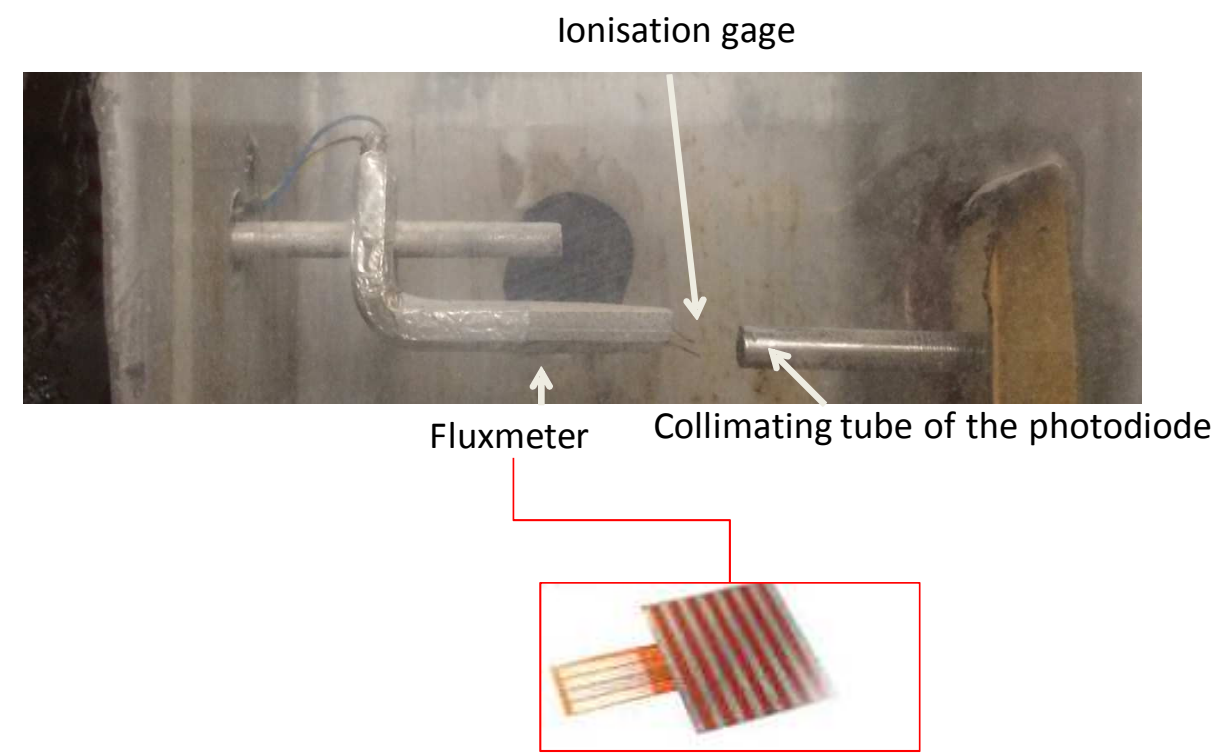

Fig. 6. Transducers arrangement and details of the fluxmeter

\section{Results}

\subsection{Combustible mixtures}

A large number of experiments were performed using methane-air mixtures with and without particles in suspension. Some tests were done with aluminium dust air mixtures. The characteristics of the dusts are given in table 1 and the particle size distribution in figure 7 under the fluidization conditions used in the combustion experiments. In the case of aluminium agglomerates were certainly produced and entrained given the large flowrates required to obtain a flammable mixture.

Table 1: main characteristics of the dusts.

\begin{tabular}{|l|l|l|l|}
\hline Nature & Specific mass $\left(\mathbf{k g} / \mathbf{m}^{\mathbf{3}}\right)$ & Mass median diameter $(\boldsymbol{\mu m})$ & Sauter mean diameter $(\boldsymbol{\mu m})$ \\
\hline Aluminium oxide & 3950 & 80 & 40 \\
Silicium carbide & 3210 & 30 & 15 \\
Aluminium & 2700 & 50 & 100 \\
\hline
\end{tabular}




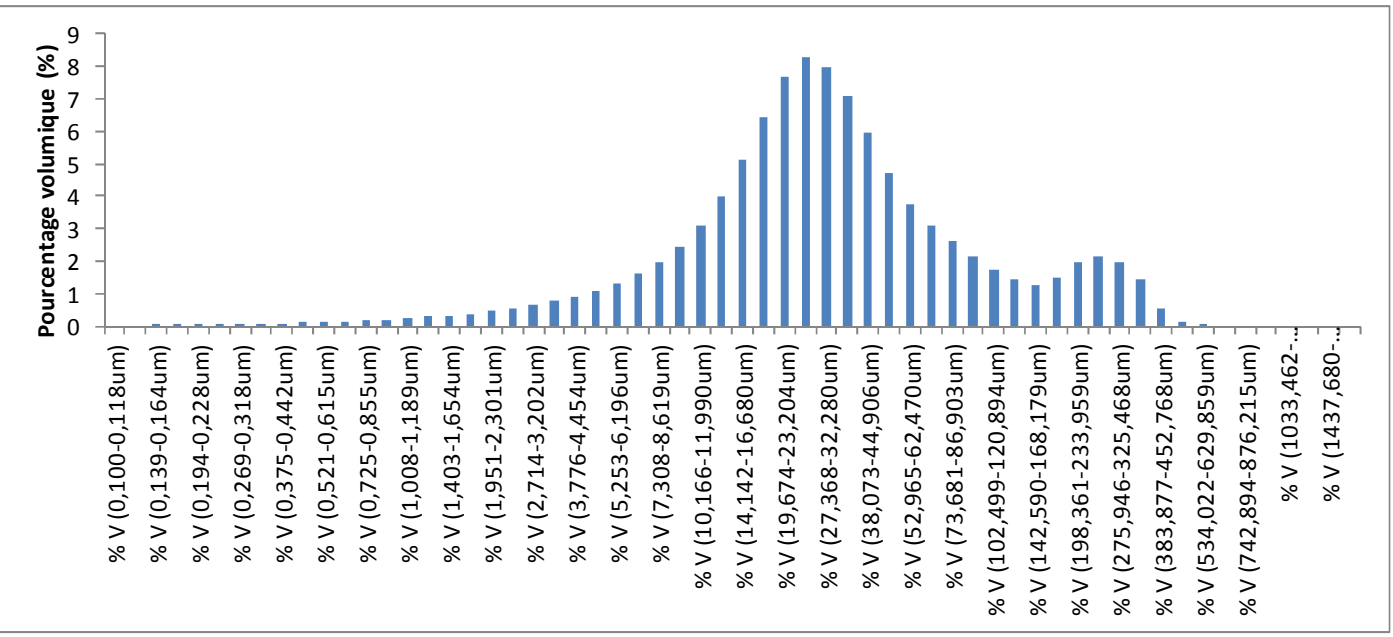

Silicium carbide

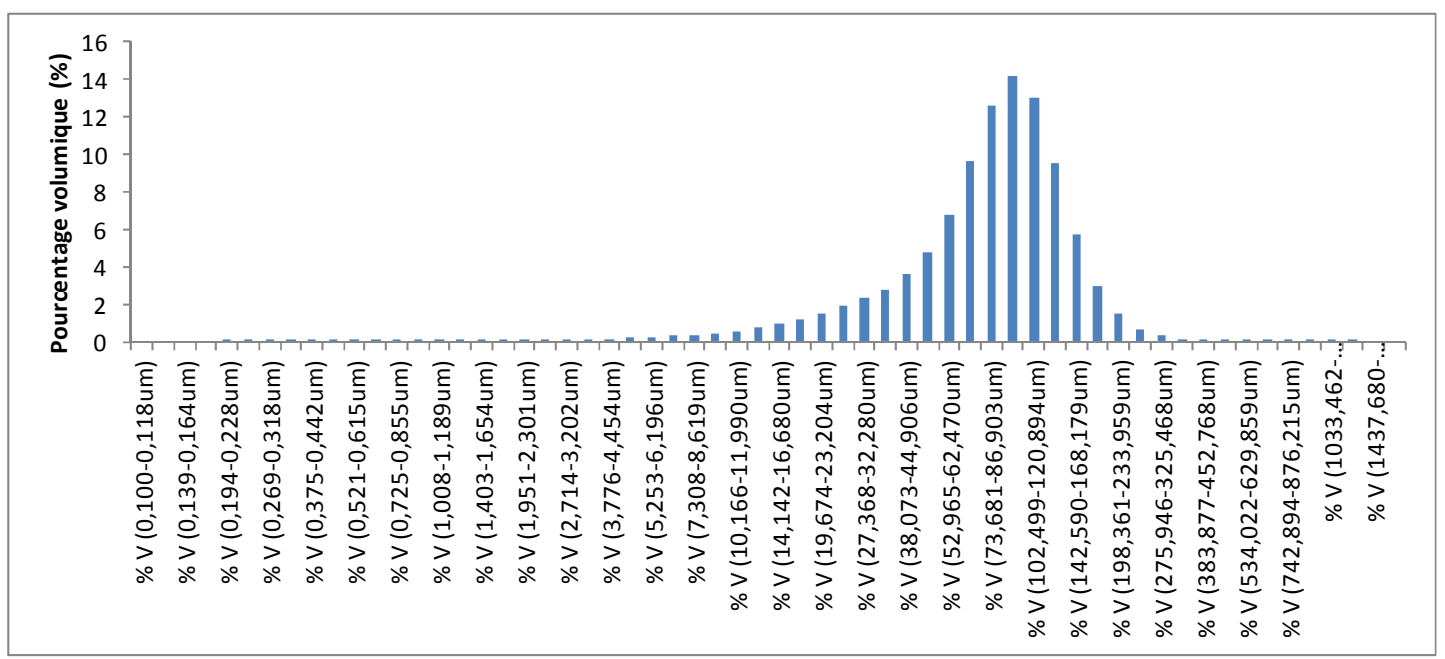

Alumina

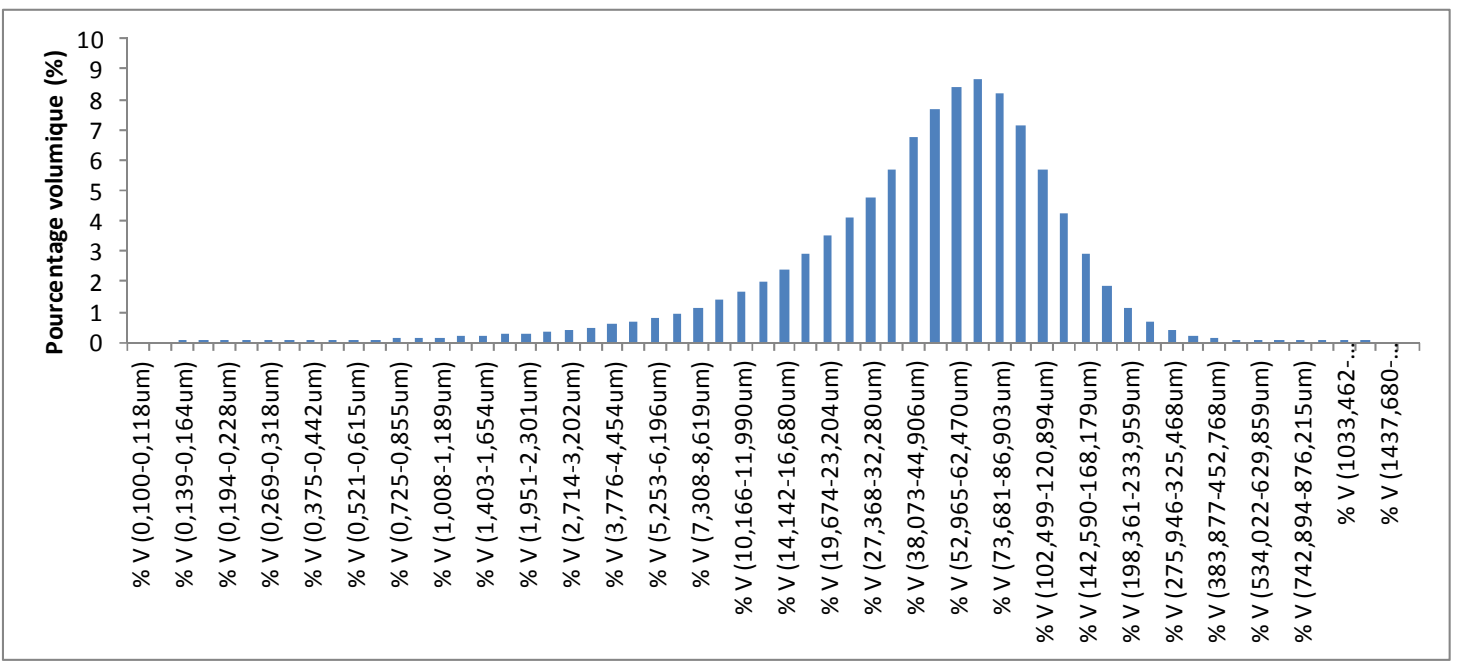

Aluminium

Fig. 7. Mass particle distribution 


\subsection{Flames}

A typical example of signals is shown on figure 8 in the case of a $8 \% \mathrm{v} / \mathrm{v} \mathrm{CH}_{4}$-air flame without particles. In this example the flame speed is about $1 \mathrm{~m} / \mathrm{s}$. At the time the flame is detected by the ionization gage, there is a discernable change in the slope of the fluxmeter signal by the radiative flux is keeping progressing after. This can be understood considering that most of the radiative flux is emitted by the burned gases $\left(\mathrm{CO}_{2}\right.$ and $\left.\mathrm{H}_{2} \mathrm{O}\right)$ i.e. behind the active burning zone.

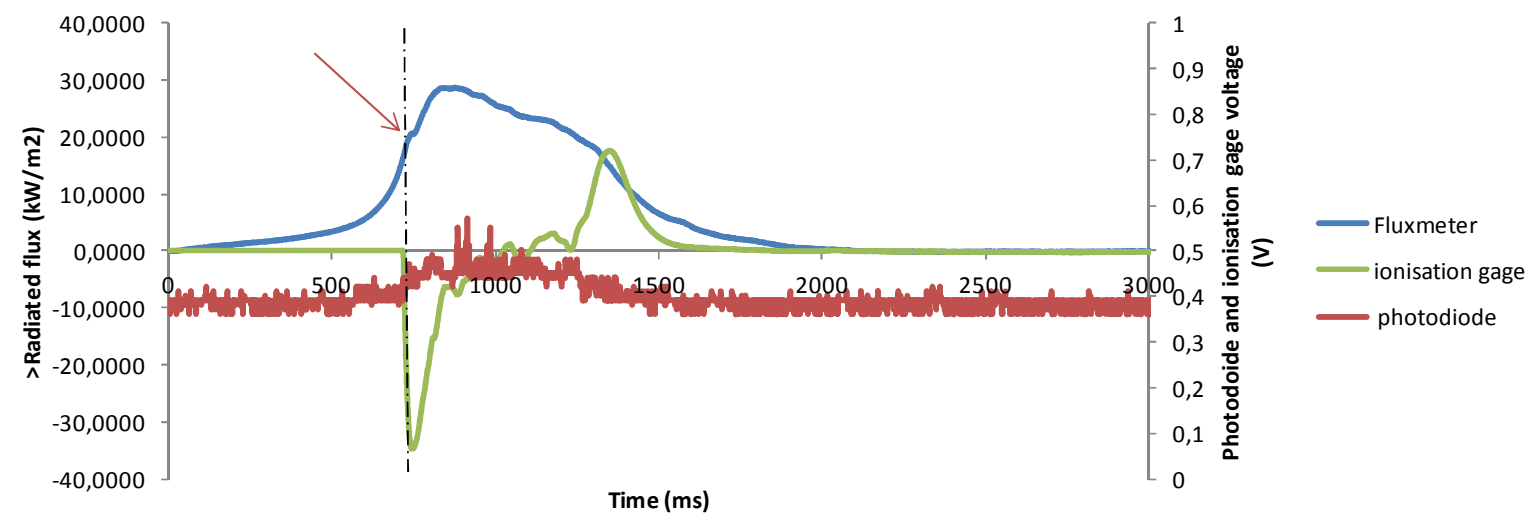

Fig. 8. Signals delivered by the transducers (10\% v/v $\mathrm{CH}_{4}$-air mixture)

Remember that the fluxmeter is "looking" in the direction of the flame so that it should detect something right from the ignition and the level of the signal should increase as the flame front approaches the transducer. A traditional graphs showing the evolution of view factor between radiating/absorbing surfaces is given on figure 9. Assuming the flame front is a flat emitting large surface $(10 \mathrm{~cm} \times 10 \mathrm{~cm})$ and the transducer a small flat surface $(2.5 \mathrm{~cm} \times 2.5 \mathrm{~cm})$, the evolution of the view factor is superimposed under the form of red stars connected by a red line. Clearly, the shape of this curve resembles that of the fluxmeter signal before the flame arrival.

The photodiode signal starts increasing about $50 \mathrm{~ms}$ before the detection of the flame front suggesting some light is detected when the flame is at $5 \mathrm{~cm}$ from the probe. This should come from some reflections on the side walls. But the level is negligibly small. 


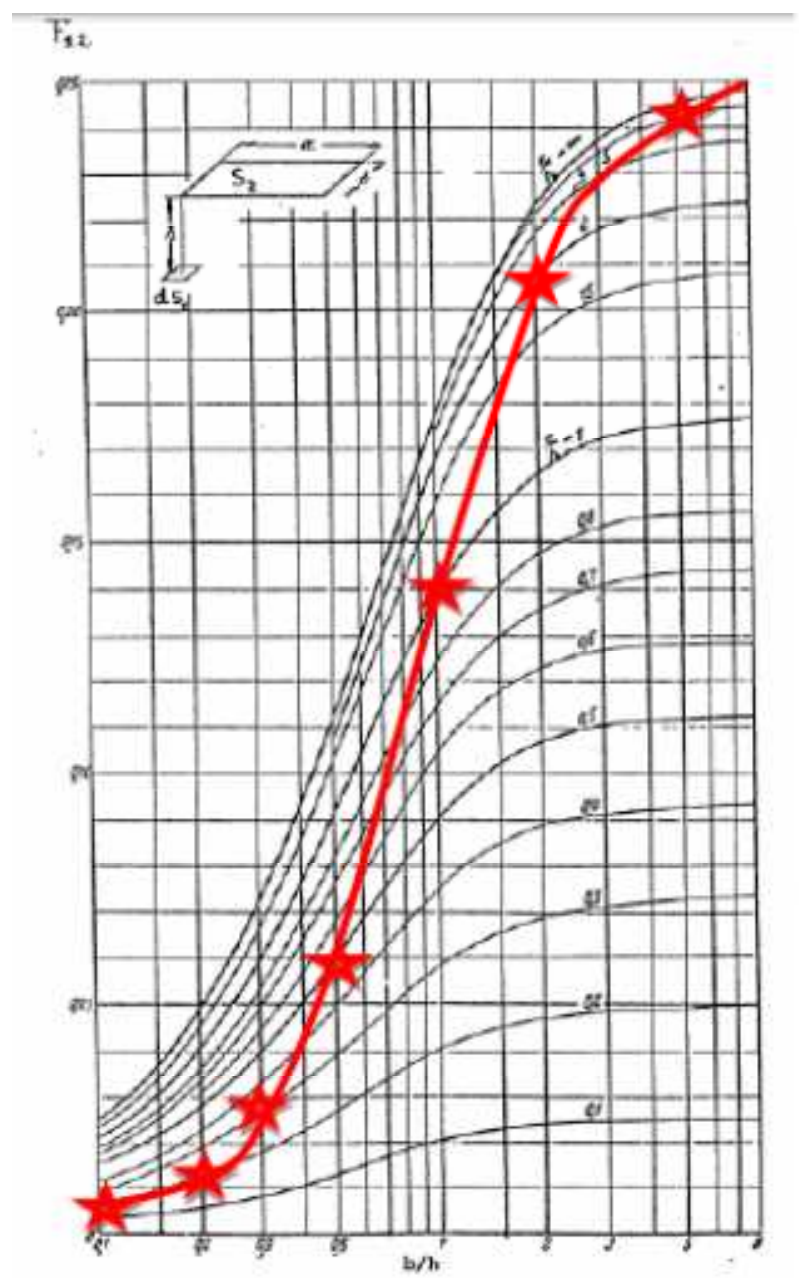

Fig. 9. View factor between a large and a small emitting/absorbing surfaces

Several tests were performed at different methane concentrations. The results are presented in table 2. Note the results are reproducible. The total flux is calculated on the basis of the experimental values of $S_{\text {lad }}$ and theroretical $T_{a d}$ (Tseng and al., 1993) using expression (3):

$$
\Phi_{\text {tot }}=\rho_{g} \cdot S_{\text {lad }} \cdot\left(T_{a d}-T_{0}\right)
$$

Table 2: methane air flames heat fluxes.

\begin{tabular}{|l|l|l|}
\hline \% methane & Radiated flux $\left(\mathbf{k W} / \mathbf{m}^{2}\right)$ & Total flux $\left(\mathbf{k W} / \mathbf{m}^{2}\right)$ \\
\hline $\mathbf{5 . 8}$ & 18,4 & 180 \\
$\mathbf{5 . 8}$ & 22,6 & 180 \\
$\mathbf{7 . 8}$ & 39 & 600 \\
$\mathbf{7 . 8}$ & 40.4 & 600 \\
$\mathbf{9 . 7}$ & 60.6 & 1100 \\
$\mathbf{9 . 7}$ & 60.8 & 1100 \\
\hline
\end{tabular}

The fraction of heat radiated seems on the order of $5 \%$ in the stiochiometric conditions but as much as $10 \%$ near the flammability limits which is not illogical suggesting that heat losses by thermal radiation of the burnt gases could be the limiting mechanism near the flammability limits.

When inert dust is added, significant differences appear. 
With alumina (figure 10), the radiative flux diminishes in proportion to the concentration of added dust (Table 3). This suggests that the particles are mostly absorbing the heat of the flame, acting as a heat sink. Given the size of the particles, the characteristic heating time is about $0.1 \mathrm{~s}$ whereas the characteristic heating time of the gaseous phase by the flame is about $0.001 \mathrm{~s}$. So the particles hardly heat up in the flame front but much later in the plume. Their temperature may not increase enough for them to radiate significantly. With $200 \mathrm{~g} / \mathrm{m}^{3}$ of alumina, the maximum flame temperature could theoretically drop by 15 to $20 \%$ so from about $2000^{\circ} \mathrm{C}$ to $1700^{\circ} \mathrm{C}$. This temperature is that of a flame propagating in a $8 \% \mathrm{v} / \mathrm{v}$ methane air flame (without dust). In this case, it can be seen from table 2 that the radiated heat flux amounts $20 \mathrm{~kW} / \mathrm{m}^{2}$ which is very close from the data of table 3 . The photodiode signal increases more progressively that with pure methane air flames but the amplitude are higher (double). All of this would also suggest that the emissivity of alumina is not zero but rather low in agreement with recent data (Rozenbaum and al., 2009)

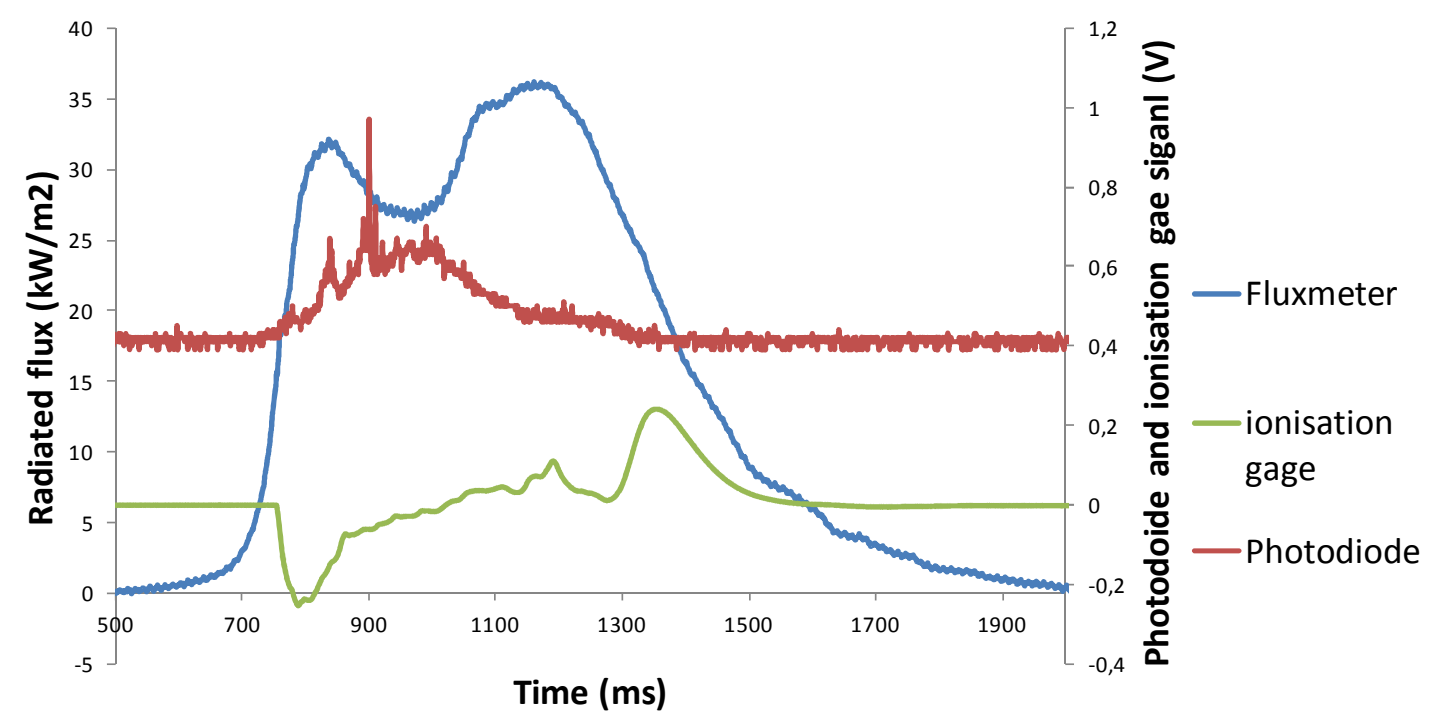

Fig. 10. Signals delivered by the transducers $\left(10 \% \mathrm{v} / \mathrm{v} \mathrm{CH}_{4}\right.$-air mixture with $290 \mathrm{~g} / \mathrm{m}^{3}$ of alumina)

Table 3: alumina dust methane air flames heat fluxes.

\begin{tabular}{|l|l|l|}
\hline \% methane & Mass particle concentration $\left(\mathbf{g} / \mathbf{m}^{\mathbf{3}}\right)$ & Radiated flux $\left(\mathbf{k W} / \mathbf{m}^{\mathbf{2}}\right)$ \\
\hline $\mathbf{1 0}$ & 90 & 44.6 \\
$\mathbf{1 0}$ & 190 & 42 \\
$\mathbf{1 0}$ & 290 & 36 \\
\hline
\end{tabular}

With SiC particle (figure 11), the radiated flux is much higher than with the pure gaseous mixture when the dust concentration is $500 \mathrm{~g} / \mathrm{m}^{3}$ but smaller for a higher concentration (800 $\mathrm{g} / \mathrm{m}^{3}$ ). These dust concentrations might be too large since a proportion of the dust can fall down in the maps of time between the interruption of the flow and the ignition. There are indicative. Nevertheless, SiC particles are very small and their heating time is only a few ms comparable to that of the flame front so that a large proportion of the particle may reach a very high temperature. The coefficient of emissivity of $\mathrm{SiC}$ is high (Zolotarev, 2007) which may explain the increase in the radiative flux even though the flame temperature may drop 
because of the energy being absorbed (Table 4). When the mass particle concentration is even larger, the second aspect may dominate (heat absorption) and the radiated flux drops. The photodiode signal increases more progressively that with pure methane air flames but is much larger.

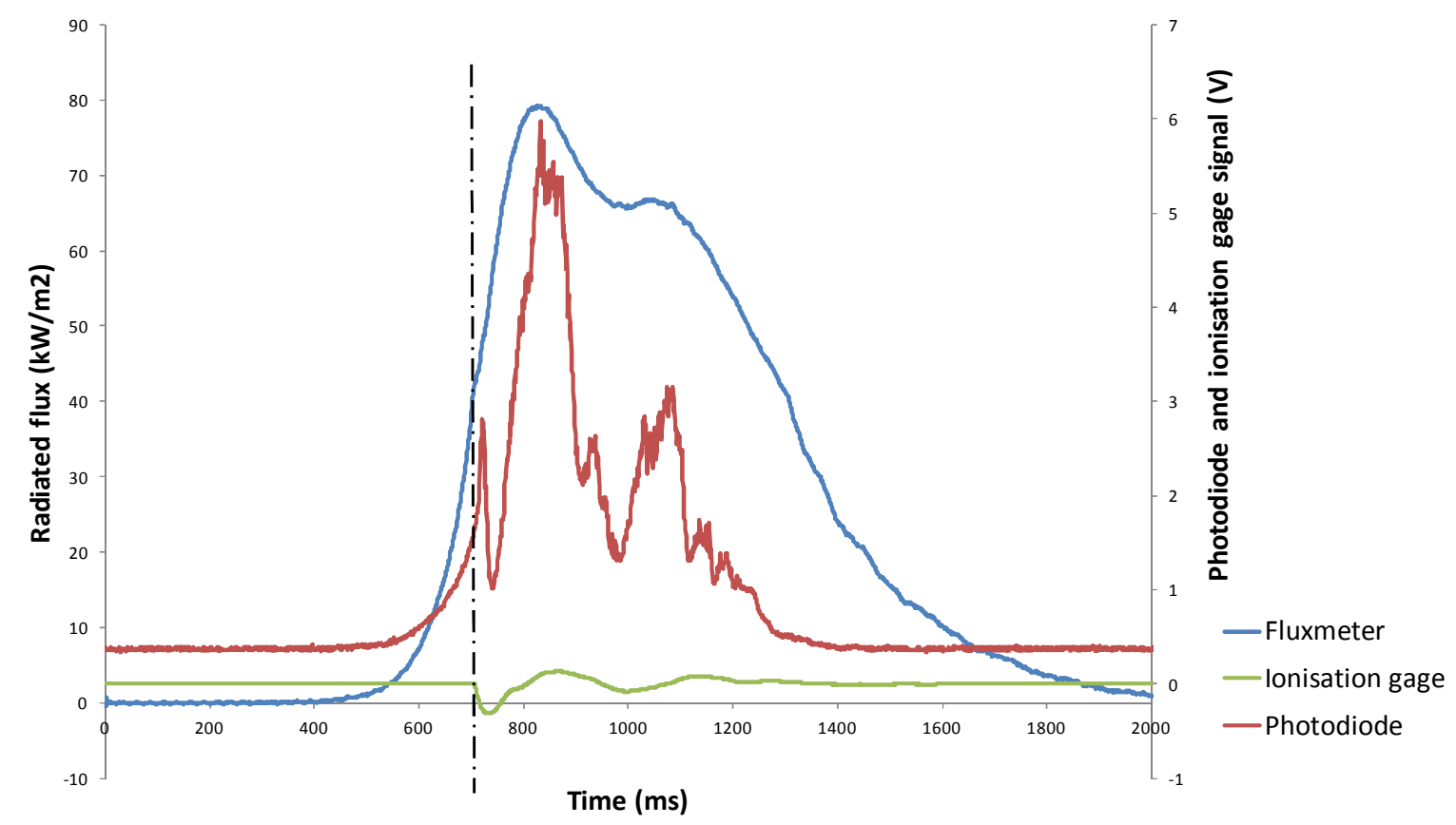

Fig. 11. Signals delivered by the transducers (10\% v/v $\mathrm{CH}_{4}$-air mixture with $500 \mathrm{~g} / \mathrm{m}^{3}$ of $\left.\mathrm{SiC}\right)$

Table 4: SiC dust methane air flames heat fluxes.

\begin{tabular}{|l|l|l|}
\hline \% methane & Mass particle concentration $\left(\mathbf{g} / \mathbf{m}^{3}\right)$ & Radiated flux $\left(\mathrm{kW} / \mathbf{m}^{2}\right)$ \\
\hline $\mathbf{1 0}$ & 500 & 80 \\
$\mathbf{1 0}$ & 800 & 54 \\
\hline
\end{tabular}

With Al dust air flames (figure 12- table 5), the radiated flux is smaller than with the methane-air mixture whereas the signal delivered by the photodiode in on the order of magnitude of the SiC-methane-air flames. This contradiction might be due to the deposition of aluminium dust on the fluxmeter which could have blurred out the transducer. But this may not be the most probable. The IR photodiode is in fact targeted on the visible spectrum and only near IR. It could have captured predominantly the chemiluminescence of the combustion (AlO band ; Grégoire and al., 2007) but not the rest of the spectrum. The fluxmeter captures a much larger spectrum and, traditionally, the contribution of chemiluminescence to the overall radiated energy is small (a few bands only). And since previous tests showed that alumina does not seem to be strongly radiating the resulting total flux might be limited. Moreover, in the present experimental situation, the particle is quite large, presumably because of agglomerates, so that most of the combustion (of the largest agglomerates), might occur downstream in the combustion products and in a cooler manner (figure 13). 


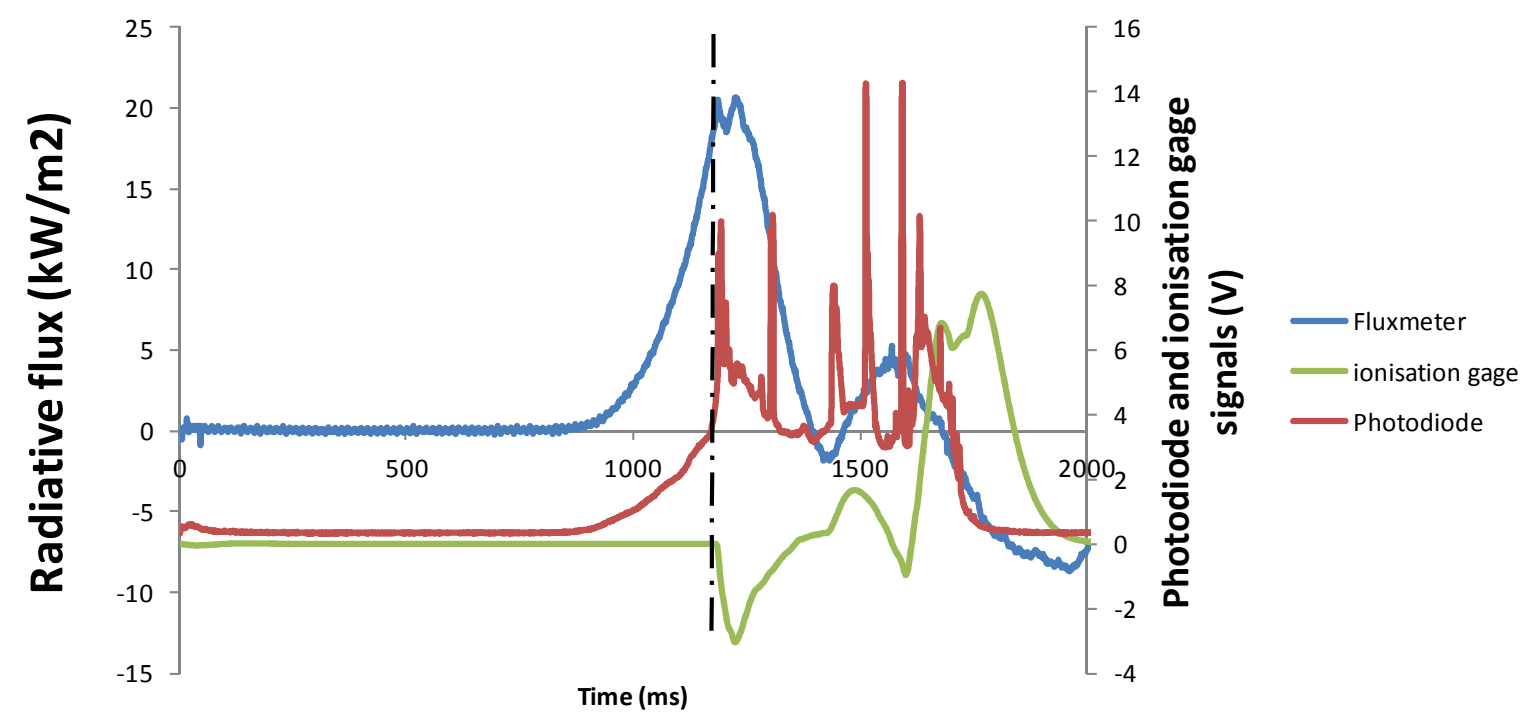

Fig. 12. Signals delivered by the transducers Al dust-air mixture with $250 \mathrm{~g} / \mathrm{m}^{3}$ of $\mathrm{Al}$

Table 5: Al dust air flames heat fluxes.

\begin{tabular}{|l|l|}
\hline Mass particle concentration $\left(\mathbf{g} / \mathbf{m}^{\mathbf{3}}\right)$ & Radiated flux $\left(\mathbf{k W} / \mathbf{m}^{2}\right)$ \\
\hline 270 & 40 \\
300 & 16 \\
250 & 20 \\
\hline
\end{tabular}

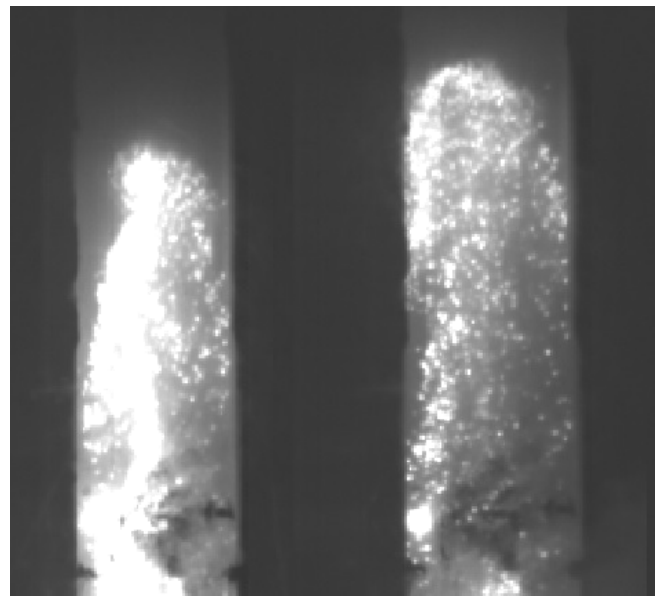

Fig. 13. Photograph of the flame front showing luminous agglomerates burning (Al dust-air mixture with $250 \mathrm{~g} / \mathrm{m}^{3}$ of $\mathrm{Al}$ )

\section{Conclusion and perspectives}

In this paper, new results concerning the amount of heat radiated by a propagation flame in a dust suspension were obtained. Methane-air mixtures were first seeded with inert particles. It appears that alumina particles radiated little and act more as heat sinks. SiC particles promote greatly the thermal radiation. Aluminium dust air mixtures (rather coarse particles) do no seem to radiate much, even less than stiochiometric methane-air mixtures. 
Further testing are currently being done, changing the size of the particles and checking the influence on the flame speed. 


\section{References}

HSL, (2009). Research Report RR718

Proust C., Guessasma M., Saleh K., Fortin J. (2013). Amplification des effets des explosions sous l'effet du rayonnement thermique . Communication au XIVeme congrès de la SFGP, Lyon, oct 2013, France

Janès A., Chaineaux J. (2010), «Explosions de poussières dans les lieux de travail», document from INRS n ${ }^{\circ} 2331-220-10$

Eckhoff, R.K. (2003). Dust explosions in the process industries. Third edition. Gulf Professional Publishing, Amsterdam

Proust C. (2006), "Flame propagation and combustion in some dust-air mixtures", J. Loss Prev. Process Ind., vol. 19, 2006

Snoeys J., Leprette E., Proust C., Jamois D., Going J. (2011), « The role of turbulence in explosion protection design", ISHPMIE, 2010, awarded best experimental paper

Vignes A. (2008), “Évaluation de l'inflammabilité et de l'explosivité des nanopoudres : une démarche essentielle pour la maîtrise des risques ", thèse de doctorat, INPL.

Dufaud O., Traoré M., Perrin L., Chazelet S., Thomas D., « Experimental investigation and modeling of aluminum dust exploions in the 201 sphere », J Loss Prev. Process Ind., vol. 23 , pp. 226-236

Cassel H. M., Das Gupta A. K., Guruswamy S. (1949), « Factors affecting flame propagation through dust clouds", 3rd Symposium (International) on Combustion, pp. 185-189.

Van de Hulst H.C. (1981), « Light scattering by small particles », Dover publications, NewYork, ISBN 0-486-64228-3

Bazyn T., Krier H., Glumac N. (2007), "Evidence for the transition from the diffusion limit in aluminum particle combustion”, Proc. Comb. Inst., vol. 31, pp 2021-2028

Mohan S., Mikhaylo A., Trunov A., Dreizin E.L. (2009), "On possibility of vapor-pahse combustion for fine aluminum particles", Comb. And Flame, vol. 156, pp. 2213-2216

Huang Y., Risha G.A., Vang V., Yetter R.A. (2007), "Combustion of bimodal nano/microsized aluminum particle in air”, Proc. Comb. Inst., vol. 31, pp 2001-2009

Huang Y., Risha G.A., Vang V., Yetter R.A. (2009), "Effect of particle size on combustion particle in air", Comb. and Flame, vol. 156, pp. 5-13

Escot-Bocanegra P. (2007), "Etudes expérimentales et modélisation de la combustion des nuages de particules micrométriques et nanométriques d'aluminium", Mémoire de thèse, Université d'Orléans

Goroshin S., Mamen J., Higgins A., Bazyn T., Glumac N., Krier H. (2007), "Emission spectroscopy of flame fronts in aluminum suspensions", Proc. Comb. Inst., vol. 31, pp 2011-2019

Kudryavtsev V.M., Sukhov A.V., Voronetskii A.V., Shpara A.P. (1982), "Combustion of gaseous suspensions of metal powders (three zone model)", Comb. Expl. Shock Waves, vol. 81, pp. 625-631

Deshaies B., Joulin G. (1985), « Radiative transfer as a propagation mechanism for rich flames of reactive suspensions ", SIAM J. of Applied Math., vol 46

Bidabadi M., Zadsirjan S., Mostafavi S.A. (2013), "Radiation heat transfer in transient dust cloud flame propagation", J. Loss Prev. Process Ind. In press

Schevchuk V.G., Bezrodnykh A.K., Boichuk L.V., Kondrat'ev E.N. (1988), "Laminar flame propagation in air suspensions of metal powders", Comb. Expl. Shock Waves, vol. 88, pp. 201-205 
Schevchuk V.G., Kondrat'ev E.N., Zolotko A.N., Smirnov V.V. (1983), “Conditions of flame propagation in aerosuspensions of metallic particles", Comb. Expl. Shock Waves, vol. 82, pp. 557-561

Tseng L.K, Ismail M.A., Faeth G.M. (1993), "Laminar Burning Velocities and Markstein Numbers of Hydrocarbon/Air Flames", Combustion and flame vol. 95, pp. 410-426

Rozenbaum O., De Sousa Meneses D., Echegut D. (2009), «Texture and Porosity E ects on the Thermal Radiative Behavior of Alumina Ceramics », International Journal of Thermophysics, 2009, vol. 30 (2), pp.580-590.

Zolotarev V. M. (2007), "High temperature spectral emissivity of SiC in the IR range", Optics and spectroscopy, vol. 103, pp. 592-602

Grégoire Y., Strutzer M.O., Khasainov B.A., Veyssiere B. (2077), "Investigation of the Behaviour of Aluminium Particles in the Burnt Products of Heterogeneous Explosives", $21^{\text {st }}$ ICDERS, Poitiers, France, july 2007 